\title{
O Doente de Hanseníase em Campinas: Uma Perspectiva Antropológica ${ }^{1}$
}

\section{People with Leprosy in Campinas, Brazil: An Anthropological Perspective}

\author{
Marcos S. Queiroz ${ }^{2}$ \\ Maria Angélica P. Carrasco ${ }^{3}$
}

QUEIROZ, M. S. \& CARRASCO, M. A. P. People with Leprosy in Campinas, Brazil: An Anthropological Perspective. Cad. Saúde Públ., Rio de Janeiro, 11 (3): 479-490, Jul/ Sep, 1995.

This article studies the life experiences of people with leprosy and their intra-domiciliary families in Campinas, Brazil, based on an analysis of their representations concerning health, disease, and treatment. Taking their living and working conditions as the background, the study sheds light on the strategies that allow them to adapt to social and family life, to obtain a livelihood, and to establish familiarity with the disease process. The article focuses particularly on the way such individuals deal with the problems of regaining their health, in addition to evaluating governmental and nongovernmental health services.

Key words: Leprosy; Hansen's Disease; Representations, Disease.

\section{INTRODUÇÃO}

Este artigo focaliza o problema da hanseníase sob o ponto de vista das representações dos doentes e comunicantes a da relação destes com os serviços de saúde públicos a eles destinados. No Brasil, a hanseníase atinge um número superior a quinhentas mil pessoas, grande pane das quais em idade produtiva, influenciando negativamente o seu trabalho, a formação da sua família e a sua integração social. A doença apresenta também neste país a maior taxa de crescimento do mundo, constituindo um dos mais sérios problemas de saúde pública.

\footnotetext{
${ }^{I}$ A pesquisa em que se baseia este artigo contou com a apoio financeiro da Federação de Apoio à Pesquisa do Estado de São Paulo e do Conselho Nacional de Desenvolvimento Científico a Tecnológico.

${ }^{2}$ Núcleo de Estudos Psicológicos, Universidade Estadual de Campinas. Rua das Orquídeas, 587, Campinas, SP, 13087-370, Brasil.

${ }^{3}$ Departamento de Enfermagem, Faculdade de Ciências Medicas, Universidade Estadual de Campinas. Rua das Orquídeas, 587, Campinas, SP, 13087-370; Brasil.
}

Por representação social entendemos um tipo de saber, socialmente negociado e contido no senso comum, que permite ao indivíduo uma visão de mundo e o orienta nas estratégias que desenvolve em seu meio social. Somente no interior de um determinado contexto social e cultural é que as representações adquirem sentido e significado.

É redundante afirmar aqui a importância não só para o desenvolvimento das áreas acadêmicas relacionadas com a sociologia e antropologia da medicina e saúde, como também para a otimização dos serviços de saúde, de um conhecimento mais profundo da experiência subjetiva da aflição e doença. Basta lembrar que esta experiência, na sua interação com outras subjetividades, constitui a matéria-prima de uma realidade cultural mais ampla e de formas sociais mais cristalizadas e objetivas.

Nesta perspectiva, o estudo das representações sociais necessita de uma abordagem compreensiva que percebe o ator social como um agente que interpreta o mundo à sua volta com uma atitude que contém intenções e, portanto, um projeto de ação (Schutz, 1973).

O problema do estudo das representações não é simples, uma vez que configurá-las sob 
uma determinada interpretação teórica significa, necessariamente, dimensioná-las a partir de aspectos limitados que certamente reduz a sua complexidade e, em conseqüência, as empobrece. Como muito bem nos lembram Alves \& Souza (1994), a ambição de se chegar a generalizações científicas expressas nas tentativas de se resumir as ações sociais, culturais e psíquicas a uma "geometria do vivido" ou a uma "gramática das ações", além de limitadora, é ilusória enquanto pretende descrever completamente um fenômeno deste tipo.

Levando em conta esta postura, o objetivo deste estudo pretende descer à microsubjetividade da experiência relativa à hanseníase, procurando, ao mesmo tempo, remetê-la a um nível sociológico e cultural mais amplo. Não é propósito deste trabalho realizar uma análise lingüística do discurso contido nas representações. Consideramos importante trazer à tona um número considerável de trechos de entrevistas com o propósito de enriquecer o trabalho e lembrar que, por mais sofisticada que seja a teoria científica, a realidade sempre possui o poder de diluí-la em sua incomensurável grandeza. Ao invés de usar os fatos para confirmar uma determinada teoria, esta pesquisa, pelo contrário, se utiliza de várias abordagens teóricas como instrumentos que realçam alguns pontos relevantes da realidade.

\section{METODOLOGIA DE INVESTIGAÇÃO}

A pesquisa de campo transcorreu durante $o$ ano de 1992 e parte de 1993 . Foram pesquisadas 34 famílias, envolvendo 45 doentes de hanseníase e 164 comunicantes, todos eles domiciliados no município de Campinas. Deste universo, foram diretamente entrevistados 90 indivíduos, sendo 33 doentes a 57 comunicantes. Trata-se de uma população pobre, sendo a maioria constituída de imigrantes provenientes da zona rural, cujos membros partilham condições precárias de vida no interior de um contexto mais amplo de instabilidade econômica, política e social.

Dessa população, apenas 2 famílias, levando-se em consideração fatores tais como renda, nível de educação a habitação, podem ser consideradas como de classe média e 7 de classe média-baixa. As demais 25 , podem ser divididas entre 14 pobres a 11 miseráveis residentes em barracos, em favelas. Este quadro é consistente com a representação corrente de que a hanseníase é uma doença típica da pobreza.

Não houve necessidade de se utilizar um critério estatístico amostral para a escolha das 34 famílias pesquisadas. Partindo do pressuposto de que apenas uma minoria se interessa em explicar teoricamente a sua experiência de vida, esta minoria consistiu o objeto de interesse desta pesquisa. A metodologia qualitativa já demonstrou em várias ocasiões a utilidade deste enfoque, uma vez que permite a expressão do que a maioria da população experimenta, sente, pensa e faz, mas não expressa dentro de um quadro de referência formalizado e coerente, deixando esta tarefa para os seus "intelectuais" (Turner, 1960).

As famílias estudadas foram constituídas a partir de doentes sob tratamento poliquimioterápico inscritos no programa de controle de hanseníase do Centro de Saúde I de Campinas. Como a poliquimioterapia está trazendo um novo alento no tratamento da hanseníase, com a perspectiva de redução significativa no tempo de tratamento, tanto da parte da população doente como da equipe médica, tem ocorrido um maior envolvimento na obtenção da cura.

A partir do pressuposto de que um número em torno de 30 famílias iriam constituir uma população adequada para os propósitos desta pesquisa, foram sorteados entre os doentes 70 nomes. Os 34 efetivamente pesquisados o foram a partir da disponibilidade, aceitação a disposição de contribuir para a pesquisa. Em geral, as famílias mostraram-se bastante motivadas para a concessão de entrevistas, de modo que este número foi obtido a partir das primeiras 41 tentativas.

De um modo geral, as entrevistas duraram 2 horas, sendo que, em alguns casos, mais de uma entrevista foi produzida para o mesmo grupo familiar com o intuito de checar certas questões. $\mathrm{O}$ motivo da entrevista foi explicado logo no começo da mesma como coleta de material para um livro, o que em geral foi aceito sem problemas. Com a exceção de uns poucos doentes que vivi- 
am isolados, a grande maioria das entrevistas foi realizada coletivamente, reunindo a maior parte possível de membros maiores de 16 anos.

\section{COSMOLOGIA SOBRE SAÚDE, DOENÇA E HANSENÍASE}

Pensar sobre saúde e doença, no contexto das famílias pesquisadas, deixa de ser uma questão meramente teórica, à medida que envolve um evento concreto de doença com implicações incapacitantes na condução de trabalho manual e carregada de significados simbólicos que remetem a uma situação de exclusão e estigma.

Centrando a questão especificamente na hanseníase, o contágio através do microorganismo foi amplamente reconhecido como uma condição crucial, mas que não reflete a causa fundamental do desenvolvimento da doença. As entrevistas mostraram que, num nível mais profundo, o surgimento da doença referiu-se quase sempre a um processo de desequilíbrio no relacionamento com a vida, mais especificamente com o trabalho ou com o meio social e familiar. As condições que geram estresse emocional foram consideradas as favoritas para o surgimento da grande maioria das doenças, inclusive a hanseníase. Quando o indivíduo se considera forte, com boa saúde, ele tende a desdenhar o risco de contágio.

Neste contexto, o tratamento da hanseníase deve ser realizado de duas maneiras, uma específica, que se refere predominantemente à medicina moderna, aos medicamentos químicos e aos procedimentos ambulatoriais e hospitalares. Num nível mais amplo, no entanto, o tratamento refere-se ao restabelecimento de um equilíbrio perdido nem sempre possível de ser atingido. A grande maioria das entrevistas revela a crença de que o mero tratamento médico, não indo às causas profundas da doença, é um procedimento apenas parcialmente eficaz, uma vez que a situação de desequilíbrio encarregar-se-ia de promover a recorrência da doença.

De um modo geral, as entrevistas mostram também que a saúde é espontaneamente identificada com um estado ideal que pode se perder no relacionamento do indivíduo com três fatores fundamentais, além das determinações do destino ou da vontade de Deus.
Em primeiro lugar, acredita-se que o indivíduo tende a adoecer quando passa a conviver com vícios a maus hábitos, negligenciando cuidados essenciais com o corpo. Inserem-se neste caso a falta de higiene e o convívio com a bebida, cigarro ou outros agentes tóxicos. Neste caso, o processo envolve culpa do indivíduo pelo aparecimento da doença.

Em segundo lugar, encontra-se o meio ambiente mais amplo que foge ao controle do indivíduo e, no entanto, se impõe refletindo uma má qualidade de vida. São exemplos deste caso a alimentação pobre ou insuficiente, a poluição, as condições adversas de trabalho, a falta de recursos médicos a todas as formas de tensão presentes na luta pela sobrevivência em meio urbano. No meio rural, o obstáculo maior encontra-se no clima, no trabalho sob sol, chuva, calor a frio. Tanto no meio urbano quanto no rural o trabalho em geral é percebido como o elemento fundamental que gera vida, enquanto possibilidade de sobrevivência individual e familiar e, ao mesmo tempo, doença, enquanto produz tensão e desgaste, principalmente para o pobre.

Um terceiro fator refere-se à insatisfação com a vida, seja ela social familiar ou individual. Neste caso, reconhece-se que a saúde depende de um estado emocional positivo que, todavia, algum estímulo externo pode retirar e confundir o indivíduo numa síndrome amplamente reconhecida como nervoso, uma condição que se acredita anteceder à grande maioria das doenças, entre elas a hanseníase. O nervosismo é associado às preocupações de toda sorte e às frustrações, que envolvem tanto as situações particulares de vida restritas à família, como as mais gerais relacionadas com a instabilidade econômica a social. As entrevistas abaixo ilustram a importância do equilíbrio emocional no restabelecimento de uma doença:

"Quando a gente morava na roça, não tinha nem médico mas a gente tinha saúde boa porque o ar não é poluído e a comida era melhor, sem química. Lá a gente não passava tanto nervoso, nem tinha tanta preocupação. $O$ dinheiro não era tão importante. Aqui, se a gente fica sem dinheiro, desempregado, a 
gente passa raiva a isso faz a gente ficar doente". (Comunicante, 51 anos, do lar) "A nossa sociedade é muito corrupta, a gente ganha pouco dinheiro e vive nervosa, insatisfeita. Isso leva à doença, porque a base da saúde é estar de bem consigo mesmo e com a sociedade. Aqui em casa, todos têm algum tipo de problema de saúde e a causa é a insatisfação com o emprego, com a poluição e com a corrupção que a gente sabe que acontece no governo".

(Comunicante, 26 anos, operária)

\section{"Para tratar a curar a hanseníase, a} pessoa precisa de paciência e calma. Se ela for ansiosa e nervosa aí não tem jeito. Foi assim com o meu marido que se tratou direitinho e teve alta em 5 anos. Já a minha irmã nunca teve um ambiente bom com sua família, ela segue direitinho o tratamento, mas vive tendo crise, febre e depressão. Não é possível para um doente se recuperar no ambiente negativo em que ela vive".

(Comunicante, 74 anos, aposentada)

"Eu fiquei doente por causa da falta de paz, da infelicidade no casamento. Quando estou nervosa, o corpo fica enfraquecido, sem resistência e, como a comida de pobre já não tem muita substância, é difícil repor as energias. É aí que a doença pega. Quando descobri que meu marido tinha outra mulher, os meus nervos ficaram abalados e a minha doença só pode ter vindo disso. A cura está demorando para vir por causa de tanta infelicidade".

(Doente, 61 anos, faxineira de firma)

\section{MEDICINA POPULAR E HANSENÍASE}

Entre a população estudada, o campo da medicina popular manifesta-se em duas áreas distintas: a medicina caseira baseada principalmente nas ervas medicinais e a medicina religiosa baseada principalmente no benzimento. Estas duas áreas são de uso comum e generalizado entre os entrevistados. Apenas duas famílias reportaram não empregar normalmente ervas medicinais e apenas três reportaram que, por princípio, não recorrem e nunca recorreram a benzedores.

A medicina religiosa constitui uma área extremamente importante no contexto da medicina popular, produzindo uma cosmologia que inclui noções bem-definidas de causação de doenças produzidas pelo envolvimento negativo do indivíduo com o seu meio social e familiar mais imediato.

A crença de que emoções negativas produzidas contra alguém podem desestabilizá-lo emocionalmente a predispô-lo a contrair doenças é um caso em questão. Acredita-se que mulheres e, principalmente, crianças são muito mais susceptíveis de serem vítimas desse fenômeno, principalmente da inveja, o mais comum de todos os sentimentos negativos. Para a hanseníase, no entanto, uma simples emoção negativa foi considerada insuficiente para iniciar o processo da doença. Mais do que isso, as entrevistas reportam a períodos mais intensos de dificuldade física a emocional.

O recurso a agentes religiosos com o propósito de restaurar o equilíbrio emocional perdido ocorre principalmente entre mulheres e crianças, sendo que os homens tendem a usar estes agentes apenas em casos considerados mais graves. Embora haja a crença de que tais agentes teriam o poder de curar muitas doenças, em geral, com algumas exceções, não se inclui a hanseníase entre elas. Para este caso, estes agentes contribuiriam para extirpar o nervosismo e gerar harmonia interior, considerada indispensável para a cura. Para isso, mais importante do que a ação de tais agentes, foi considerada a atitude positiva da família para com o doente.

O uso de chá caseiro baseado em ervas medicinais mostrou-se um instrumento de uso generalizado entre as famílias pesquisadas. Não foi possível encontrar uma sequer que, contra algumas indisposições ou mal estares, tivesse deixado de recorrer a esta prática. Especificamente para a hanseníase, no entanto, apenas uma minoria utilizava esse tipo de medicamento. As entrevistas abaixo ilustram esses vários aspectos:

"Foram tantas vezes que tive problemas de saúde e os médicos não conseguiram curar que já perdi a conta. Quando deixava de 
tomar medicamentos e decidia que Deus era o meu médico eu sempre consegui sarar das minhas doenças".

(Comunicante, 48 anos, ajudante de pedreiro)

"No serviço, a gente trabalha

honestamente, mas sempre tem alguns que têm inveja, que ficam "fuchicando" a vida da gente. A gente vai passando nervoso, vai passando para o coração e vai ficando doente. A inveja é a arma do incompetente".

(Comunicante, 51 anos, do lar)

“ Já fui internado no hospital por causa de dores fortes na barriga e os médicos me deram alta sem desconfiar que era apendicite. Depois de ter sido tratado espiritualmente na Umbanda, as dores voltaram e o mesmo médico que tinha achado que não era nada percebeu que eu precisava operar do apêndice. Foram as orações que deram um pouco de luz a abriram a mente dele. Eu operei e nunca mais tive nada".

(Doente, 50 anos, motorista aposentado)

"Eu já tive tuberculose e me curei com ervas caseiras. No começo eu me tratei com um médico que me entuchou de vários remédios que me faziam ficar muito pior do que estava. Um dia eu criei coragem e joguei todos eles fora, comecei a fazer tratamento por minha conta a acabei sarando dessa doença. Hoje, eu sigo o tratamento no Centro de Saúde, mas tomo ervas medicinais porque eu sei que elas ajudam". (Doente, 71 anos, pensionista)

\section{DIAGNÓSTICO, TRATAMENTO E CONHECIMENTO DA HANSENÍASE}

Noventa por cento dos depoimentos relativos à experiência pessoal da hanseníase coletados por esta pesquisa apresentam um ponto em comum, o fato de o paciente ter passado por pelo menos um diagnóstico médico errado. $\mathrm{O}$ envolvimento de vários médicos a muitos anos de tratamento equivocado foi o cenário mais comum que envolveu a experiência vivida da grande mai- oria dos pacientes pesquisados. Nesse contexto, os depoimentos foram eloqüentes no sentido de revelar o fato de que os médicos em geral receberam treinamento insuficiente e inadequado para lidar com várias doenças endêmicas prevalentes no Brasil. Quando se pensa em hanseníase, em particular, esta deficiência revela-se de um modo ainda mais pronunciado.

$\mathrm{O}$ reconhecimento de qualquer sintoma corporal depende de dois fatores: primeiro, da percepção de algo anormal no corpo e, segundo, de um conhecimento que remeta esta percepção a uma situação de doença. No caso da hanseníase, a junção desses dois fatores é difícil de ocorrer uma vez que, como muito bem demonstrou Boltanski (1979), a percepção de um sintoma corporal depende, em grande medida, de uma referência simbólica que o situe no interior de um sistema de conhecimento e crenças. Só então este sintoma poderia ser reconhecido e, a partir daí, iniciativas tomadas. Como o capital taxonômico das classes trabalhadoras manuais é pequeno com relação a eventos corporais, esta percepção fica prejudicada, a não ser quando o sintoma evolui para formas significativas de dor ou incapacidade para o trabalho.

No caso da hanseníase, esta situação pode ser ainda mais dramática, já que os sintomas no início da doença não são muito notáveis e nem prejudicam o desempenho no trabalho. Este motivo, juntamente com a ausência de busca ativa por casos por parte da rede pública de serviços de saúde, além do despreparo dos médicos para diagnosticar a doença, explica o fato de o diagnóstico da hanseníase ser geralmente tardio. A maior parte das entrevistas realizadas mostra uma estória semelhante a esta contada abaixo:

\section{"A minha avó ficou mais de 10 anos fazendo tratamentos que não tinham nada a ver com hanseníase. No começo, os médicos achavam que era reumatismo, depois que começou a aparecer umas feridas, eles diziam que era por causa da diabetes. Só recentemente um médico suspeitou de hanseníase e os exames do Centro de Saúde confirmaram esta doença”. (Comunicante, 37 anos, cozinheira)}

O tratamento da hanseníase é difícil e demorado, exigindo um tempo mínimo de dois anos no caso do paciente estar se submetendo à 
poliquimioterapia. No caso do tratamento tradicional, o tempo é muito maior, podendo chegar a 15 ou mais anos, dependendo do caso. Embora mais eficaz, a poliquimioterapia não é tolerada por alguns pacientes devido aos seus efeitos colaterais. Um deles, amplamente reconhecido como muito desagradável, é o escurecimento da pele. Outros referem-se a indisposições estomacais, prejuízo para o funcionamento dos rins a indisposição geral para o exercício de atividades físicas a mentais.

Além dos antibióticos, o tratamento demanda uma disciplina que altera muitos hábitos do paciente, exigindo abstinência de bebidas alcoólicas e exercícios físicos diários para os tendões e filamentos nervosos, principalmente dos membros superiores a inferiores. Os antibióticos são fornecidos gratuitamente pelo Centro de Saúde que acompanha a evolução do tratamento, exigindo a presença mensal do paciente.

Setenta a cinco por cento dos pacientes não seguem adequadamente o tratamento, principalmente no que se refere aos exercícios físicos, os quais se mostraram incompatíveis para quem trabalha com o corpo o dia inteiro e chega cansado a casa. Quanto ao uso dos antibióticos, a maioria segue o tratamento, apesar do mal-estar que eles provocam. Com um índice de $43 \%$ de consumo de bebida alcoólica entre os doentes, a abstinência necessária por causa do uso de antibióticos está longe de ser generalizada. Uma percentagem significativa de $20 \%$ interrompe momentaneamente por sua própria conta e risco o consumo de medicamentos quando ocorre um mal-estar mais intenso decorrente do seu uso.

A pesquisa constata que a mudança de nome de lepra para hanseníase adotada pelo Ministério da Saúde e seguida pelas Secretarias Estaduais concorre positivamente para se considerar esta doença como outra qualquer, reduzindo a conotação negativa com ela associada. De um modo geral, cerca de $50 \%$ da população entrevistada ou não considera que hanseníase e lepra são a mesma doença, ou considera ambas como estágios muito diferentes da mesma doença, sendo que a lepra aparece como uma manifestação muito mais grave.

Embora a hanseníase tenha se mostrado como uma doença merecedora de preocupação, quando comparada com outras doenças graves tais como o câncer ou, principalmente, a AIDS (uma referência constante para situar positivamente a hanseníase), então, ela voltava a ser considerada banal.

Os trechos de entrevista abaixo ilustram estes aspectos:

"Eu não sei o que é lepra, já ouvi falar que é uma doença muito ruim que dá feridas cascudas que arrebentam na pele deixando a pessoa suja a fedida. Graças a Deus eu nunca vi esta doença. Hanseníase é o que eu tenho, começa com um formigamento na pele. Não dá para explicar muita coisa por que a gente não tem estudo e não pensa muito no assunto". (Doente, 62 anos, dona de casa)

"Quando comecei a fazer os exames eu tinha medo que fosse AIDS. A médica fez muitos mistérios antes de me dizer o que eu tinha e eu fiquei muito assustado. Quando soube que tinha hanseníase me senti até melhor. Os médicos explicaram que, fazendo o tratamento, a doença deixaria de ser contagiosa. Acho que serei curado e não estou preocupado".

(Doente, 40 anos, pequeno empresário)

"Antes, os leprosos eram enxotados; hoje, o problema com a AIDS é muito maior, e a hanseníase passou a ser uma doença normal, mas mesmo assim, é melhor evitar comentar com os outros sobre o assunto". (Doente, 40 anos, comerciante)

De um modo geral, o conhecimento sobre a doença demonstrado pela população estudada, em termos como a compreende a ciência ocidental moderna, é rudimentar. Enquanto $25 \%$ dos comunicantes e pacientes mostram não saber praticamente nada a respeito, os demais conhecem apenas rudimentos que, no máximo, são equivalentes aos cartazes informativos no Centro de Saúde.

Em quatro casos, comunicantes sequer sabiam que havia um doente de hanseníase na família. Em várias outras situações, foi encontrada uma 
atitude de discrição exagerada que considera que querer saber muito sobre o assunto seria uma forma de indelicadeza para com o doente.

A pesquisa constata também que a comunicação entre o pessoal do Centro de Saúde e os pacientes é precária. Cerca de $85 \%$ da população pesquisada de doentes não entende as informações prestadas pelo Centro de Saúde ou as considera incompletas para responder às muitas dúvidas. A grande maioria da população entrevistada considera que o governo deveria explicar melhor sobre a hanseníase em programas de televisão, que é o veículo de comunicação mais acessível. As entrevistas abaixo ilustram esses vários aspectos:

"Num desses dias, fui à reunião no centro de saúde e eles explicaram uma porção de coisas que não entendi bem. A única coisa que entendi é que a Hanseníase pega". (Doente, 47 anos, do lar)

\section{"Eu acho que deveria estar mais a par das coisas. Por que não se dá mais esclareci- mento e informação na TV já que todo mundo vê TV? Só assim o povo teria mais esclarecimento, mais informação e saberia se prevenir da doença". \\ (Comunicante, 37 anos, ajudante de pedreiro) \\ RELACIONAMENTO SOCIAL, FAMILIAR E DE TRABALHO}

Embora a hanseníase seja uma doença que, uma vez tratada, apresenta possibilidades significativas de cura e não apresenta risco de contágio, em função do preconceito cultural, apesar dos esforços do pessoal da saúde, ainda persiste uma situação de estigma em relação à doença.

O termo estigma é utilizado segundo o conceito desenvolvido por Goffman (1963) que encontra nesta manifestação sociocultural três tipos fundamentais: as abominações do corpo, os defeitos de caráter e a proveniência social. É evidente que, no contexto da hanseníase, o estigma se refere ao descrédito, à desqualificação e à marginalização social em função de deformidades físicas do paciente. Uma vez que um indivíduo é estereotipado com tal rótulo social, que significa impor-lhe uma marca que, de um certo modo, o reduz a uma condição in- ferior ao padrão mínimo atribuído à condição humana, restaria a ele duas possibilidades: ou se adequar ao papel marginal a ele designado, ou tentar "encobrir" as marcas que caracterizam o estereótipo estigmatizante.

Aceitar o papel social significaria, no Brasil, antes da segunda metade deste século, segregarse da família a da sociedade a confinar-se num dos leprosários disponíveis, submetendo-se a um tratamento que não tinha qualquer possibilidade de controlar a doença. $\mathrm{Na}$ Índia, conforme o relato de Waxler (1981), ainda hoje em dia, para um indivíduo socialmente reconhecido como leproso, não há alternativa ao abandono do emprego, à separação da família e a exclusão do meio social. Procurar, como mendigo, uma cidade grande é tudo o que lhe resta.

Enquanto a tendência, no meio cultural da Índia, seria o indivíduo conformar-se com o papel social a ele atribuído e, nos Estados Unidos, agir agressivamente contra este tipo de estereótipo, no Brasil, a nossa pesquisa sugere que há uma forte tendência para o "encobrimento" da doença com o apoio da família nuclear e dos serviços de saúde.

A grande maioria dos doentes entrevistados revela não haver preconceito entre os membros da família nuclear. Em três ocasiões, no entretanto, este preconceito foi explicitado, sendo que em dois casos houve separação do casal (depois reconciliados) a uma exclusão do meio familiar em função da doença. Quanto ao meio social e de trabalho do paciente, a atitude de encobrir a hanseníase é generalizada.

As entrevistas mostram que o preconceito existe a aqueles que não se preocuparam em preservar a sua imagem social, sofreram um processo de degradação, exclusão ou, no caso de trabalho, demissão. Houve pronunciamentos que, mesmo sabendo não haver possibilidade de contágio, revelam uma atitude de aversão ao doente, como se ele tivesse se tornado, na acepção de Douglas (1966), impuro após lidar com situações perigosas. Os trechos abaixo mostram como esses aspectos são experimentados:

\section{"O meu marido deve ter pego hanseníase} por causa do tipo de serviço que ele faz, do entulho que ele mexe e carrega no caminhão. A doença pode ter vindo também das suas viagens, ele vai muito à Bahia e só 
pode ter trazido de lá, daqui é que ele não pegou". (Comunicante, 43 anos, aposentada)

"Para os vizinhos, eu digo que faço um tratamento para uma anemia forte. Se alguém ficasse sabendo que tenho hanseníase, iria espalhar e eu quero ser tratado como pessoa normal. Aqui em casa, ninguém faz diferença comigo, mas em qualquer outro lugar eu sei que haveria problema".

(Doente, 62 anos, dona de casa)

"É importante saber que, com o tratamento, a doença não fica contagiosa porque eu cuido de 2 crianças no meu emprego e não gostaria que eles pegassem hanseníase. Se os meus patrões souberem que tenho essa doença, tenho certeza que iriam me demitir". (Doente, 36 anos, empregada doméstica)

"Entre os parentes eu não noto preconceito, mas na Igreja crente que freqüentava eu notei. Algumas pessoas vinham me visitar todos os domingos e, quando souberam da minha doença, deixaram de vir. Eu tive que sair da Igreja”. (Doente, 48 anos, do lar)

"Eu fico muito triste vendo meu filho sem emprego. Ele conseguiu um emprego, mas teve logo que parar por causa de uma crise de neurite. Quando voltou do tratamento, encontrou sua carteira assinada com demissão. Ele ficou com tanta raiva que parou o tratamento para hanseníase. Ele se tornou uma pessoa muito revoltada e ultimamente deu para beber".

(Doente, 60 anos, pensionista)

Os doentes que apresentam sinais da doença mais pronunciados como manchas em partes visíveis do corpo ou deformidades físicas encontram-se numa situação de estigma ainda mais pronunciado. Para esses indivíduos, tudo é muito mais difícil como, por exemplo, arranjar um emprego, ter amigos, procurar uma companheira a constituir uma família. Isolado, o indivíduo internaliza algum tipo de culpa. Mesmo quando ele é bem sucedido em camuflar a doença, a preocupação de ser descoberto é um tormento constante, principalmente para os mais jovens. As entrevistas abaixo ilustram esse aspecto:

"Eu fico muito revoltado com minha doença. Eu tenho que andar sempre com camisa de manga comprida a não posso ir à praia e usar bermudas. Pior que tudo é não poder tomar as cervejas com os amigos".

(Doente, 29 anos, lojista)

"A hanseníase é uma doença enviada como castigo de Deus. Eu vivo me perguntando onde errei. Eu sou muito nervoso e revoltado por causa disso. Não tenho namorada e não gosto de sair de casa. As pessoas evitam se aproximar de mim por causa da deformação da minha mão esquerda. O que eu mais gostaria é de arranjar um trabalho e me sentir útil. Eu bebo para ficar mais calmo". (Doente, 23 anos, desempregado)

\section{AVALIAÇÃO DO GOVERNO, DO SERVIÇO E DA MEDICINA}

A população pesquisada avaliou unanimemente a situação do país como negativa e a situação pessoal a familiar como difícil. Quando a atenção foi focalizada no Centro de Saúde específico para o tratamento da hanseníase, a avaliação foi melhor do que a do sistema de saúde em geral, chegando a ser positiva em cerca de $29 \%$ dos casos. Os que avaliaram o serviço como adequado com restrições chegam a $43 \%$ a os que o consideraram precário e insuficiente totalizam $28 \%$.

Os que espontaneamente avaliaram positivamente o serviço, deram como razão principalmente o fato de ele ser grátis. Foi também bastante mencionada a qualidade no atendimento, principalmente de um ou outro médico ou enfermeira. As maiores restrições, pela ordem de importância, foram a demora no atendimento, a falta de esclarecimento para com os doentes e a falta de atenção de médicos a pessoal de enfermagem.

O processo de avaliação de um serviço público apresenta um forte componente de subjetividade que mesmo uma pesquisa qualitativa algumas vezes não consegue controlar. Em 
pelo menos uma ocasião, a ambigüidade da avaliação foi óbvia. O paciente considerou excelente o serviço, mas interrompeu o tratamento porque avaliou que não houve acerto para com o seu caso específico.

Esta maneira de pensar a agir, embora tenha aparecido em apenas uma única ocasião de forma explícita é, provavelmente, muito mais comum. Avalia-se a pessoa do médico enquanto um ser humano sem que ocorra uma associação com sua competência profissional aplicada num determinado caso. Não se espera que o médico acerte sempre o diagnóstico e, quando ocorre esta falha, cabe ao paciente procurar outro médico a tentar uma melhor sorte. Ser um bom médico, neste sentido, mais do que "acertar" os remédios, significa ser atencioso a conseguir estabelecer uma conexão emocional para com o paciente. As entrevistas abaixo ilustram esses aspectos:

"A situação do país está péssima. Não há emprego, muitos dos meus colegas mais antigos viraram bandidos. A gente que procura viver honestamente, sofre, não encontra oportunidade".

(Doente, 26 anos, ajudante de pedreiro)

"No Centro de Saúde, o atendimento é demorado demais, um exame não leva menos do que 3 meses. O governo precisaria dar mais apoio para a saúde, mas atualmente, isso parece ser impossível".

(Doente, 40 anos, pequeno empresário)

"Os médicos do centro de saúde são bons, eles só não acertaram os remédios que fizeram muito mal para mim. Por isso é que parei o tratamento de hanseníase”.

(Doente, 24 anos, contínuo de firma)

"Ser atendida com atenção e carinho é o que a gente espera de um serviço de saúde. A gente vai lá nervosa, cheio de problema a se não for bem recebida é pior do que se não tivesse ido".

(Doente, 61 anos, faxineira).

\section{EXPECTATIVAS, ESTRATÉGIAS E ATITUDES}

Um indivíduo ou sua família pode reagir ao diagnóstico da hanseníase com indiferença, ou como se fosse uma catástrofe terrível. As razões para essa discrepância repousam, em boa medida, no nível de educação a de renda a que pertence o doente. De um modo geral, encontramos o seguinte padrão: as duas famílias de classe média a as sete famílias de classe média baixa perceberam o diagnóstico como algo muito negativo, embora a grande maioria dos tipos de hanseníase nesses extratos sociais represente formas menos graves. Entre as famílias de classe baixa, os que receberam o diagnóstico com indiferença foi de cerca de $46 \%$, ainda que, de um modo geral, os tipos de hanseníase nesses extratos sociais representem formas mais graves por causa do diagnóstico tardio. Os trechos de entrevista abaixo ilustram esses pontos:

"Eu não liguei para o diagnóstico, não achei que faria muita diferença, a vida iria continuar da mesma forma. O que eu mais queria era um alivio para o meu sofrimento que melhorou muito depois do começo do tratamento. Com a licença que eles me deram, eu fiquei 3 meses afastada do serviço e os sintomas melhoraram. Aqui em casa, entre os meus parentes e vizinhos ninguém ligou para o fato de eu ter hanseníase".

(Doente, 61 anos, pensionista)

"Quando soube que tinha hanseníase, não senti nada, me conformei. A gente não tem tempo para pensar muito no problema. Eu me preocupo mais com o que eu terei de pôr na mesa amanhã". (Doente, 62 anos, dona de casa)

"Quando ouvi do médico que tinha hanseníase, fiquei tão transtornado que nem consegui ouvir as explicações. Foi a minha mulher quem me acalmou me dizendo que o problema não era tão grave como eu imaginava. A doença estava no início, não era contagiosa e a cura não levaria tanto tempo".

(Ex-doente, técnico especializado, 53 anos)

A identificação de saúde com capacidade de trabalho e bem-estar, principalmente entre as 
famílias de classe social mais baixa, prejudica a percepção de que o tratamento para hanseníase realmente possa conduzir à cura. Para essas famílias, é estranho que um tratamento que causa tantas indisposições e mal-estares promova, ao mesmo tempo, a cura da doença. Em várias ocasiões, as primeiras sensações negativas provocadas pelos medicamentos foram identificadas como uma situação em que o médico não "acertou". Esta interpretação responde pela maioria dos casos de abandono do tratamento, um fato que, segundo estimativas do Centro de Saúde corresponde a cerca de $10 \%$ dos pacientes que iniciam tratamento. Entre os quatro doentes entrevistados que abandonaram o tratamento, todos eles de classe social baixa, nem mesmo saber que a doença poderia piorar levando a deformações incapacitantes impediram esta tomada de decisão.

O desânimo pela demora no tratamento e a dúvida sobre a melhora foram constantes à grande maioria das famílias. As entrevistas abaixo ilustram esses pontos:

"Por causa da doença, tive que parar de trabalhar, de me divertir e de ir a bailes para encontrar uma namorada. Não tenho esperança de cura depois de 4 anos de tratamento sem resultado. Com a vida que eu tenho, não me sinto nada feliz".

(Doente, 28 anos, aposentado)

"Eu fiquei com hanseníase e tratei por pouco tempo. Não trato mais porque no centro de saúde eu tinha que ficar esperando mais de 3 horas para ser atendido e eu não tenho tempo. Por enquanto, o problema é só no nariz e nariz tanto faz. Eu me sinto bem e se piorar, se pegar o braço e as pernas, eu vejo o que vou fazer".

(Doente, 33 anos, caminhoneiro)

"Já estou mais de 2 anos tratando e esperava uma reação melhor. As coisas não foram exatamente como o médico disse, apesar de seguir o tratamento direitinho, inclusive a fisioterapia. Às vezes, eu desanimo e penso que a doença não tem cura e que o tratamento só serve para mantê-la estacionada". (Doente, 40 anos, pequeno empresário)
"Para ser sincera, eu acho que tomo remédio errado. Foi assim com o meu irmão que só melhorou depois que o médico mudou o seu remédio. Como eu sempre tenho mal estar por causa desse mesmo remédio, eu fico cismada".

(Doente, 33 anos, cozinheira)

"Como me dei muito mal com o tratamento, procurei um outro médico que achou que a mancha fosse micose. Faz 2 meses que estou passando as pomadas que ele receitou sem sentir qualquer melhora. Poderia ter dado certo, mas como não deu, vou retomar ao centro de saúde, mas vou querer fazer os exames outra vez porque eu desconfio que houve erro no teste".

(Doente, 33 anos, operário)

\section{CONCLUSÃO}

Esta pesquisa mostra, antes de tudo, a baixa prioridade que a hanseníase recebe por parte da sociedade em geral e da medicina em particular. Embora dados epidemiológicos revelem que a epidemia hansênica esteja crescendo no Brasil a uma grande velocidade, esta informação não parece sensibilizar a sociedade e o poder público no sentido de promover um enfrentamento do problema. A proporção de diagnósticos equivocados, resultado direto da ignorância generalizada dos médicos em geral com respeito a hanseníase, revela também que, focalizar doenças deste tipo não é prioritário pelo sistema de educação médica.

Um outro ponto importante refere-se ao precário envolvimento do paciente com o seu tratamento, reflexo do deficiente processo de informação e acompanhamento prestado pelo Centro de Saúde. Esse aspecto resulta de uma opção de política da saúde que, ao mesmo tempo, privilegia os aspectos biológicos do tratamento a negligencia os aspectos sócioculturais necessariamente presentes no cuidado para que ocorra o processo da cura.

A pesquisa mostra que a grande maioria dos doentes e comunicantes pesquisados sabe muito pouco sobre a doença a reivindicam uma melhor comunicação com a equipe de saúde, visando um relacionamento mais harmônico com o processo de tratamento. Esta reivindicação encontra-se in- 
tegrada com uma visão que percebe tanto a saúde como a doença como resultantes, em grande medida, do relacionamento do ser humano com o seu meio social, familiar e de trabalho.

Outras pesquisas mostram que este tipo de representação é partilhada por muitas outras sociedades e culturas, inclusive sociedades complexas como mostra o estudo de Herzlich (1973) conduzido em Paris, um meio urbano cosmopolita. Ficar doente ou curar uma doença, segundo esta representação, depende do modo de vida tomado num sentido mais amplo que, sem negar os aspectos biológicos da doença e da cura, leva em conta a dimensão simbólica presente nos valores que dão sentido à vida, à doença e à morte.

Ainda que haja um consenso nas ciências sociais, particularmente nas áreas da antropologia da medicina e sociologia da medicina, de que a compreensão da saúde e da doença não pode prescindir a fatores sociais e culturais, esta perspectiva só recentemente tem-se aberto de um modo mais consistente para as ciências biológicas. No entanto, os estudos realizados com placebos, com a atitude emocional em relação à cura e, principalmente, com o estresse têm revelado aspectos que as ciências sociais, a psicologia e, ironicamente, as representações do senso comum de muitas sociedades já conheciam, ou seja, o fato de que tanto a saúde como a doença dependem de componentes subjetivos e emocionais relacionados com a experiência de vida. Intervir nestas dimensões pode ser eficaz para muitos problemas que a medicina insiste em focalizar sob o ponto de vista estritamente biológico. Capra (1993: 319) fala com muita propriedade a respeito:

\footnotetext{
"Existe um elemento-chave no vínculo entre o estresse e a doença que ainda não é conhecida em todos os seus detalhes, mas que foi verificado por numerosos estudos: é o fato de que o estresse prolongado anula o sistema imunológico do corpo e suas defesas naturais contra infecções e outras doenças. $O$ pleno reconhecimento desse fato ocasionará uma importante mudança na pesquisa médica, fazendo com que ela deixe de lado a preocupação com microorganismos
}

e passe a estudar cuidadosamente o organismo hospedeiro e seu meio ambiente. Tal mudança é vital em nossos dias, visto que as doenças crônicas e degenerativas - que são características do nosso tempo e constituem as causas principais de morte e incapacidade - estão intimamente relacionadas com o estresse excessivo"

Este estudo assume, portanto, que, para incorporar uma dimensão holística (que integre o indivíduo com a sua dimensão social a cultural) da saúde a doença (em consonância tanto com as representações populares, como com as investigações científicas mais recentes sobre placebo a estresse), a medicina precisaria ampliar a sua base reducionista biológica e incluir dimensões sociais e culturais no enfoque da saúde e da doença. Esta perspectiva teria um efeito duplo com relação à especificidade do nosso estudo. De um lado, ela responderia à demanda de grande parte da população estudada e, de outro, muito provavelmente, produziria um impacto positivo no quadro epidemiológico de desenvolvimento da hanseníase.

\section{RESUMO}

\section{QUEIROZ, M. S. \& CARRASCO, M. A. P. O} Doente de Hanseníase em Campinas: Uma Perspectiva Antropológica. Cad. Saúde Públ., Rio de Janeiro, 11 (3): 479-490, jul/set, 1995.

Este artigo estuda a experiência de vida de doentes e comunicantes de hanseníase em Campinas, Brasil, a partir da análise de suas representações sobre saúde, doença e terapêutica. Trata-se de captar no interior das condições de vida e de trabalho destes indivíduos as estratégias que permitam adaptação ao meio social e familiar, subsistência e convivência com a doença. Atenção especial é dada à maneira pela qual estes indivíduos enfrentam o problema de manutenção e recuperação da saúde, assim como avaliam os serviços e as práticas oficiais e não-oficiais de saúde.

Palavras-Chave: Hanseníase; Lepra; Representações; Doença 


\section{REFERÊNCIAS BIBLIOGRÁFICAS}

ALVES, P. C. \& SOUZA, I. M., 1994. Escolha e Avaliação de Tratamento para Problemas de Saúde: O Itinerário Terapêutico. Texto apresentado no XVIII Encontro Anual da ANPOCS. Caxambu. (Mimeo).

BOLTANSKI, L., 1979. Classes Sociais e o Corpo. Rio de Janeiro: Graal.

CAPRA, F., 1993. O Ponto de Mutação. São Paulo: Cultrix.

DOUGLAS, M., 1966. Purity and Danger. Harmondsworth: Penguin Books.

GOFFMAN, E., 1963. Estigma. Buenos Aires: Amorrortu.

HERZLICH, C., 1973. Health and Illness - a Social Psychological Analysis. London: Academic Press.
SCHUTZ, A. 1973. Collected Papers. The Problem of Social Reality. The Haugue: Martinus Nijhoff.

TURNER, V. W., 1960. Muchona the hornet, interpreter of religion. In: In the Company of Man (J. B. Casagrande, ed.), pp. 62-84, New York: Harper.

WAXLER, N. E., 1981. Learning to be a leper: a case study in the social construction of illness. In: Social Contexts of Health, Illness \& Patient Care (E. G. Mishler, ed.),pp. 169-192, Cambridge: University Press. 